\title{
Fibrinogen-related proteins in ixodid ticks
}

\author{
Jan Sterba ${ }^{1 *}$, Jarmila Dupejova', Miroslav Fiser ${ }^{1}$, Marie Vancova ${ }^{1,2}$ and Libor Grubhoffer ${ }^{1,2^{*}}$
}

\begin{abstract}
Background: Fibrinogen-related proteins with lectin activity are believed to be part of the tick innate immune system. Several fibrinogen-related proteins have been described and characterised mainly on the basis of their cDNA sequences while direct biochemical evidence is missing. One of them, the haemolymph lectin Dorin M from the tick Ornithodoros moubata was isolated and characterised in more depth.

Results: Several fibrinogen-related proteins were detected in the haemolymph of ixodid ticks Dermacentor marginatus, Rhipicephalus appendiculatus, $R$. pulchellus, and $R$. sanguineus. These proteins were recognised by sera directed against the tick lectin Dorin $M$ and the haemagglutination activity of the ticks $R$. appendiculatus and $D$. marginatus. Cross-reactivity of the identified proteins with antibodies against the fibrinogen domain of the human ficolin was also shown. The carbohydrate-binding ability of tick haemolymph was confirmed by haemagglutination activity assays, and this activity was shown to be inhibited by neuraminic acid and sialylated glycoproteins as well as by $\mathrm{N}$-acetylated hexosamines. The fibrinogen-related proteins were shown to be glycosylated and they were localised in salivary glands, midguts, and haemocytes of D. marginatus. Hemelipoglycoprotein was also recognised by sera directed against the fibrinogen-related proteins in all three Rhipicephalus species as well as in D. marginatus. However, this protein does not contain the fibrinogen domain and thus, the binding possibly results from the structure similarity between hemelipoglycoprotein and the fibrinogen domain.

Conclusions: The presence of fibrinogen-related proteins was shown in the haemolymph of four tick species in high abundance. Reactivity of antibodies directed against ficolin or fibrinogen-related proteins with proteins which do not contain the fibrinogen domain points out the importance of sequence analysis of the identified proteins in further studies. Previously observed expression of fibrinogen-related proteins in haemocytes together with the results of this study suggest involvement of fibrinogen-related proteins in tick immunity processes. Thus, they have potential as targets for anti-tick vaccines and as antimicrobial proteins in pharmacology. Research on fibrinogenrelated proteins could reveal further details of tick innate immunity processes.
\end{abstract}

\section{Background}

Together with mosquitoes, ticks are the primary vectors of a broad-range of dangerous human and animal pathogens. Some of the well-known infections transmitted by hard ticks (Ixodidae) are Rocky Mountain spotted fever, ehrlichiosis, tick-borne encephalitis, Lyme borreliosis, theileriosis or babesiosis while soft ticks (Argasidae) are vectors of African swine fever and tick-borne relapsing fever $[1,2]$.

Tick haemolymph is a complex fluid composed of plasma and haemocytes. It serves several functions such as transportation of nutrients but it contains also the

\footnotetext{
*Correspondence: sterbaj@paru.cas.cz; liborex@paru.cas.cz

'Faculty of Sciences, University of South Bohemia, Branisovska 31, 37005

Ceske Budejovice, Czech Republic

Full list of author information is available at the end of the article
}

components of the immune system and helps the tick to fight injuries. Until now, haeme-storage proteins $[3,4]$, defensins [5-7], a tick haemolymph lectin Dorin $M$ from Ornithodoros moubata [8,9], and several others have been described.

Tick defence against pathogenic microorganisms is based on recognition of pathogen-associated molecular patterns (PAMPs) such as lipopolysaccharides or peptidoglycans with lectins [10]. Invertebrate/arthropod lectins are believed to be functional analogues of immunoglobulins due to their specific binding to surface carbohydrate structures of pathogens [11]. In arthropods, fibrinogen-related proteins (FRePs) are described as humoral factors of the innate immune system with the ability to recognise PAMPs. FRePs are molecules containing fibrinogen-related domain in the
C Biomed Central

() 2011 Sterba et al; licensee BioMed Central Ltd. This is an Open Access article distributed under the terms of the Creative Commons Attribution License (http://creativecommons.org/licenses/by/2.0), which permits unrestricted use, distribution, and reproduction in any medium, provided the original work is properly cited. 
C-terminus; some of these domains exhibit carbohydrate-binding activity $[12,13]$. FRePs from Tachypleus tridentatus (Tachylectin 5A and 5B) with highsequence homology to human ficolins selectively bind terminal $N$-acetyl group of sugars [14] and this lectinactivity is important in the innate immunity processes [12].

Lectins/FRePs have been found in several ticks [8,15-17] in the haemolymph, the midgut, and salivary glands (SGs) [reviewed in [11]]. Generally, tick lectins display affinity towards sialic acid [8] and $N$-acetyl-D-glucosamine (GlcNAc) [15] as well as galactose [17]. Several FRePencoding sequences were also described to date: Ixoderin A, Ixoderin B, Ixoderin A-like (Ixoderin ricinus), Dorin M, and OMFREP (O. moubata) [18]. The OMFREP mRNA is detected in haemocytes and SGs. Ixoderin A is expressed in haemocytes, SGs, and the midgut; Ixoderin B is expressed mainly in SGs and weakly in haemocytes [18]. Sequence similarity of the identified tick lectins with Tachylectins suggests their involvement in innate immunity [9]. Dorin $M$ is still the only purified tick lectin. It is a $640 \mathrm{kDa}$ homomer composed of subunits with $37 \mathrm{kDa}$ [8] and exhibits haemagglutination activity, which is inhibited by $N$-acetylated hexoses, $N$-acetyl neuraminic acid, and sialylated glycoproteins $[8,9]$. The protein is glycosylated and as such it is recognised by several lectins specific for high-mannose and complex glycans [8]. Three $N$-glycosylated sites described in the protein bear two high-mannose glycans with up to nine mannose residues and a core-fucosylated paucimannosic structure [19].

In $I$. ricinus, $85 \mathrm{kDa}$ lectin was partially characterised with specificity for $N$-acetyl neuraminic acid, $N$-acetyl glucosamine, and D-galactose; however, its sequence is not known [15]. The protein was localised to tick haemocytes and other tissues [16]. Haemagglutination activity of the Rhipicephalus appendiculatus haemolymph, the midgut, and SGs have been also characterised. This activity was higher in blood-fed ticks compared with unfed ticks [20].

Furthermore, hemelipoglycoprotein was recognised by serum directed against the Dorin $M$ and against the haemagglutination activity of the $D$. marginatus haemolymph [4]. However, the protein does not show similarity to fibrinogen or fibrinogen-related proteins [3]. Structural similarity of the protein to the fibrinogen domain was therefore suggested [4].

Herein, we describe reactivity of the haemolymph of several ticks with sera against the previously identified tick lectin Dorin $M$ and against haemagglutination activity of the tick haemolymph as well as with antibodies recognising the fibrinogen domain of the human ficolin. The observed fibrinogen-related proteins were further characterised in regards of their glycosylation and they were localised in tissues of the tick $D$. marginatus.

\section{Results}

\section{Tick haemolymph haemagglutination}

Haemagglutination activity (HA) analyses of tick haemolymph samples isolated from Dermacentor marginatus, Rhipicephalus appendiculatus, $R$. pulchellus, and R. sanguineus were performed using $2 \%$ suspension of rabbit erythrocytes. In all studied ticks, the haemolymph exhibited haemagglutination activity; HA titre was 512 for D. marginatus haemolymph and 192 in the case of the three Rhipicephalus haemolymphs (not shown).

Next, haemagglutination inhibition was studied using monosaccharides and glycoproteins (see Table 1). The most potent inhibitors of HA for each tick species were $N$-acetyl neuraminic acid (NeuAc) and sialylated glycoproteins. Moreover, $N$-acetylated hexosamines showed inhibition of the agglutination. However, differences in HA inhibition were detected among tick species and the highest inhibition was observed in $R$. sanguineus.

\section{Reactivity of the tick haemolymph with antibodies to putative FRePs}

We used different rabbit/mouse sera directed against potential FRePs: the tick lectin Dorin M (closely related to fibrinogen domain of ficolins); haemolymph lectin molecules with HA activity of ticks D. marginatus (anti-(DM) $\mathrm{HA}$ ) and $R$. appendiculatus (anti-(RA)HA); and immune sera raised against putative $D$. marginatus FReP proteins from this study with molecular weights of $36 \mathrm{kDa}$ (antiDMF1) and $290 \mathrm{kDa}$ (anti-DMF3). Moreover, we tested antibodies directed against $I$. ricinus lectin $(85 \mathrm{kDa})$ [16]

Table 1 Haemagglutination inhibition assays on tick haemolymph

\begin{tabular}{lllll}
\hline Saccharide/glycoprotein & D. $\mathbf{m}$. & R. a. & R. p. & R.s. \\
\hline NeuAc & 0.0625 & 0.0312 & 0.0312 & 0.0312 \\
\hline ManNAc & 0.125 & 0.0624 & 0.5 & 0.0312 \\
\hline GalNAc & 0.125 & 0.5 & 0.5 & 0.0625 \\
\hline GlcNAc & 0.125 & 0.125 & - & 0.0625 \\
\hline L-fucose & - & 0.5 & - & 0.25 \\
\hline BSM & 0.00244 & 0.0312 & 0.0312 & 0.0312 \\
\hline PSM & 5 & 0.25 & 0.5 & 0.25 \\
\hline fetuin & 1.67 & 0.5 & - & 0.0625 \\
\hline Polysialic acid & 0.208 & nd & nd & nd \\
\hline asialofetuin & 3.33 & nd & nd & nd \\
\hline
\end{tabular}

The following saccharides and glycoproteins were used: $\mathrm{N}$-acetyl neuraminic (sialic) acid (NeuAc), $\mathrm{N}$-acetyl mannosamine (ManNac), $\mathrm{N}$-acetyl galactosamine (GaINAc), N-acetyl glucosamine (GlcNAc), fucose, polysialic acid, bovine submaxillary mucine (BSM), porcine stomach mucine (PSM), fetuin, asialofetuin. Except for asialofetuin, all glycoproteins are sialylated. Concentration inhibiting HA is depicted in $\mathrm{mol} / \mathrm{l}$ for monosaccharides and $\mathrm{mg} / \mathrm{ml}$ for polysialic acid and glycoproteins. nd - not determined.

We studied haemagglutination activity in ticks D. marginatus (D.m.), R. appendiculatus (R.a.), R. pulchellus (R.p.), R. sanguineus (R.s.). 
with results corresponding to findings obtained using the immune sera against the potential FRePs (data not shown).

When assessing the presence of potential FRePs in the D. marginatus haemolymph by immunoblotting, four proteins were identified by both anti-(DM)HA and antiDorin $\mathrm{M}$ antibodies with molecular weights of approximately $36 \mathrm{kDa}, 79 / 80 \mathrm{kDa}$, and $290 \mathrm{kDa}$ under nonreducing conditions (Figure 1A). Three proteins were recognised by anti-(RA)HA serum also in $R$. appendiculatus, $R$. pulchellus, and $R$. sanguineus haemolymphs, where the molecular weights of the detected putative FReP proteins were $58 \mathrm{kDa}, 75 \mathrm{kDa}$, and approximately $290 \mathrm{kDa}$ (Figure 1B). Moreover, weak reaction was observed for a $45 \mathrm{kDa}$ protein in $R$. pulchellus (Figure $1 \mathrm{~B}$, lane 2); however, this protein was not observed in the other Rhipicephalus species. The $75 \mathrm{kDa}$ and



Figure $1 \mathrm{Imm}$ Imodetection of the putative fibrinogen-related proteins in tick haemolymph. 1A - Electrophoretically separated and electroblotted non-reduced D. marginatus haemolymph proteins immunostained using mouse anti-(DM)HA serum (lane 1) and rabbit anti-Dorin $M$ serum (lane 2). Four proteins were detected with molecular weights of approximately 36, 79/80, and 290 kDa (marked with asterisks; the $79 / 80 \mathrm{kDa}$ double-band is marked by one asterisk). 1B - Electrophoretically separated and electroblotted non-reduced R. appendiculatus (lane 1), R. pulchellus (lane 2), and $R$. sanguineus (lane 3 ) haemolymph proteins immunostained using mouse anti-(RA)HA serum. In each sample, three proteins were detected with size of 58, 75, and 185 kDa (asterisks). Furthermore, a protein band with molecular weight of $45 \mathrm{kDa}$ was observed in R. pulchellus (arrow). 1C - Electrophoretically separated and electroblotted non-reduced $R$. appendiculatus (lane 1), R. pulchellus (lane 2), and $R$. sanguineus (lane 3 ) haemolymph proteins immunostained using rabbit anti-Dorin $M$ serum. Proteins with molecular weight of 75 and $185 \mathrm{kDa}$ were detected, as in the case of anti-(RA)HA serum (asterisks).
$290 \mathrm{kDa}$ protein bands were detected also by anti-Dorin $\mathrm{M}$ serum (Figure $1 \mathrm{C}$ ).

\section{Reactivity of the putative tick FRePs with anti-ficolin antibodies}

To confirm the similarity of the identified tick proteins to the fibrinogen domain, we performed immunoblotting of haemolymph proteins from the studied ticks using two commercial antibodies directed against the fibrinogen domain of the human ficolin 1: anti-FCN1 $\mathrm{H}$ and anti-FCN S.

All four (36 kDa, 79/80 kDa, and $290 \mathrm{kDa}$ ) proteins were recognised in $D$. marginatus haemolymph by the anti-FCN1 $\mathrm{H}$ antibodies (Figure 2, lane 1). In the three Rhipicephalus species haemolymphs, only the 75 and $290 \mathrm{kDa}$ proteins were recognised (Figure 2, lanes 2, 3, and 4). Furthermore, we performed the immunoblotting on the purified hemelipoglycoprotein from $D$. marginatus [4]; the purified protein was recognised by the antiFCN1 $\mathrm{H}$ antibodies as well (Figure 2, lane 6). Recombinant human ficolin 1 was used as a control (Figure 2, lane 5). Similar results were obtained also using the second antibodies, anti-FCN1 S (data not shown).

\section{Putative FRePs in tick haemolymph are glycosylated}

Positive glycoprotein staining (either non-specific Schiff periodate staining or glycan-specific lectinoblotting) of tick haemolymph proteins revealed abundant glycosylation of proteins. Protein bands corresponding to putative FReP proteins were also positively stained (data not shown). To address the glycosylation of these proteins more specifically, we performed enzymatic deglycosylation reactions of the haemolymphs from $D$. marginatus, $R$. appendiculatus, and $R$. sanguineus ticks. After deglycosylation, putative FRePs were detected using anti-(DM)HA, anti-(RA)HA, anti-DMF1 or anti-DMF3 sera. Thus, changes in molecular weights of the putative FRePs could be detected without the interfering staining of the other haemolymph proteins.

In all cases, deglycosylation of haemolymph proteins changed the FRePs immunostaining pattern. In D. marginatus haemolymph, anti-DMF1 serum stained the $36 \mathrm{kDa}$ protein under reducing conditions. After deglycosylation with $N$-glycosidase F (cleaves off the whole $N$-glycan except for structures containing core $\alpha(1,3)$-bound fucose), reactive protein bands with molecular weights of 30,31 , 33,34 , and $36 \mathrm{kDa}$ appeared (Figure 3A). The enduring reaction of the $36 \mathrm{kDa}$ band suggests incomplete deglycosylation reaction. The anti-DMF1 serum detected also the $79 / 80 \mathrm{kDa}$ proteins, which under reducing conditions migrated as three protein bands with molecular weights of 58,60 , and $66 \mathrm{kDa}$ suggesting the presence of noncovalently bound subunits. The molecular weights of these three bands decreased after $N$-glycosidase $F$ treatment and 




Figure 2 Immunoblotting of tick haemolymph proteins with anti-ficolin antibodies. Electrophoretically separated and electroblotted non-reduced haemolymph proteins from $D$. marginatus (lane 1), R. appendiculatus (lane 2), R. pulchellus (lane 3), and $R$. sanguineus (lane 4) were immunostained using rabbit antiFCN1 $\mathrm{H}$ antibodies. Recombinant human ficolin 1 was used as a control (lane 5). Purified hemelipoglycoprotein from D. marginatus haemolymph, which was identified by MS as one of the recognised proteins was used as a control (lane 6). However, this protein does not contain the fibrinogen domain [3]. The same proteins as in Figure $1 \mathrm{~A}$ were detected in D. marginatus haemolymph (36 kDa, $79 / 80 \mathrm{kDa}$, and $290 \mathrm{kDa}$ proteins; marked with asterisks; the $79 / 80 \mathrm{kDa}$ double-band is marked by one asterisk). In Rhipicephalus ticks haemolymphs, the $72 \mathrm{kDa}$ and $290 \mathrm{kDa}$ proteins were detected, but not the $55 \mathrm{kDa}$ protein. Additionally, the purified hemelipoglycoprotein from D. marginatus was detected by the antiFCN1 $\mathrm{H}$ antibodies. Non-reduced recombinant human ficolin 1 served as a positive control. Antibodies positively reacted with subunits of the protein (approximately $30 \mathrm{kDa}$ ) as well as with higher molecular weight complexes (approximately $60 \mathrm{kDa}$, $180 \mathrm{kDa}, 250 \mathrm{kDa}, 280 \mathrm{kDa})$.

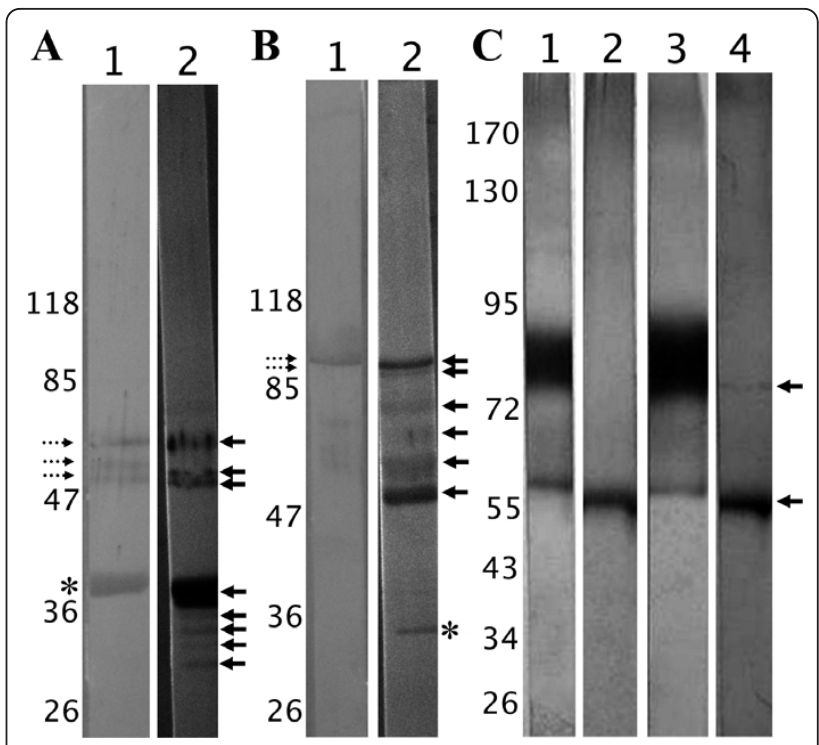

Figure 3 Deglycosylation of the putative fibrinogen-related proteins in tick haemolymph and their immunodetection. $3 \mathrm{~A}$ -

Reduced D. marginatus haemolymph proteins (lane 1) were enzymatically deglycosylated (lane 2). The FReP proteins were detected using anti-DMF1 serum, which was raised against the 36 $\mathrm{kDa}$ protein (asterisk). After deglycosylation, additional bands appeared with sizes of 31,33, and $34 \mathrm{kDa}$ (arrows). Cross-reactivity of the serum with $79 / 80 \mathrm{kDa}$ proteins was observed (bands with molecular weights of 58,60, and $66 \mathrm{kDa}$ - lane 1, dotted arrows). The molecular weight of these proteins shifted after deglycosylation and three bands were observed at 54, 58, and $63 \mathrm{kDa}$ (lane 2, arrows). 3B - Reduced D. marginatus haemolymph proteins (lane 1) a were enzymatically deglycosylated (lane 2). The FReP proteins were detected using anti-DMF3 serum, which was raised against the $290 \mathrm{kDa}$ protein. This protein is composed of two subunits which have 95 and $100 \mathrm{kDa}$ (lane 1, dotted arrows). After deglycosylation (lane 2), additional bands appeared at 50 and $74 \mathrm{kDa}$ (arrows). We observed cross-reactivity of the serum also in this case, when the same bands were observed for the 79/80 kDa proteins (lane 2, arrows) as in the case of anti-DMF1 serum (see Figure 2A). The protein band at $34 \mathrm{kDa}$ (lane 2, asterisk) is probably a protein cleavage product. $3 C$ - Reduced R. appendiculatus (lanes 1,2) and $R$. sanguineus (lanes 3,4) haemolymph proteins before (lanes 1,3) and after deglycosylattion (lanes 2,4). The FReP proteins were detected using anti-(RA)HA serum. In both tick samples (lanes 1,3), $58 \mathrm{kDa}$ band was observed and a protein smear from 75 to $90 \mathrm{kDa}$ (75 kDa protein and the subunits for $185 \mathrm{kDa}$ protein). The deglycosylation diminished the reactivity of the protein smear and only the band at $58 \mathrm{kDa}$ remained visible (lanes 2,4; arrows).

they were observed at 54,58, and $63 \mathrm{kDa}$ (Figure 3A). Same results with lower intensity were obtained for the 79/ $80 \mathrm{kDa}$ proteins also using anti-DMF3 serum (Figure 3B).

Anti-DMF3 serum stained two bands at 95 and 100 $\mathrm{kDa}$ under reducing conditions suggesting non-covalently bound subunits in the $290 \mathrm{kDa}$ protein. After the $\mathrm{N}$-glycosidase $\mathrm{F}$ treatment, four bands belonging to the protein were observed with molecular weights of 50,74 , 95 , and $100 \mathrm{kDa}$. While the larger bands suggest incomplete deglycosylation, appearance of the 50 and the 74 
$\mathrm{kDa}$ bands shows cleavage of the glycan moiety from the subunits of the $290 \mathrm{kDa}$ protein (Figure 3B). Another stained protein at $\mathrm{Mw}$ of $34 \mathrm{kDa}$ also appeared on the blot.

The reactivity of anti-(RA)HA serum with deglycosylated proteins from the Rhipicephalus ticks haemolymphs markedly decreased (Figure $3 \mathrm{C}$ ). In haemolymph under reducing conditions, the serum recognised the $58 \mathrm{kDa}$ protein and a smear from 75 to $90 \mathrm{kDa}$, which we speculate represents the $75 \mathrm{kDa}$ protein as well as the subunits of the $290 \mathrm{kDa}$ protein. After deglycosylation using Endo $\mathrm{H}$ enzyme, which cleaves between the two innermost GlcNAcs of the $N$-glycans, only one protein remained reactive with molecular weight of $56 \mathrm{kDa}$ in both $R$. appendiculatus and $R$. sanguineus haemolymphs. In $R$. sanguineus, a slight reaction at $75 \mathrm{kDa}$ was visible, representing possibly the incompletely deglycosylated protein (Figure 3C).

The $N$-glycosidase F treatment on Rhipicephalus ticks haemolymph as well as deglycosylation of $D$. marginatus haemolymph using Endo $\mathrm{H}$ enzyme resulted in disappearance of the anti-(RA)HA or anti-Dorin $M$ sera staining (data not shown).

\section{Localisation of FRePs in D. marginatus organs}

Taking advantage of specific anti-FReP sera, we performed immunolocalisation of these proteins in the midgut, SGs, and haemocytes dissected from the partially fed $D$. marginatus.

In a type III of SG acini, anti-DMF1 serum labelled structures inside the epithelial cells that surround the secretory cells (Figure 4A). In the acinus type II, positive reaction of this serum was detected inside of the secretory granules located in the cytoplasm of cells occurring near the acinar duct (b cells; Figure 4B). We observed anti-DMF1 labelling inside the midgut cells (Figure 4C) and, surprisingly, in perinuclear region of haemocytes attached to SGs (Figures 4D, E). Only haemocytes attached to SGs showed reactivity with anti-DMF1 serum while free circulating haemocytes did not appear to contain FRePs (data not shown).

Anti-DMF2 serum showed the presence of FRePs in the cytoplasm of midgut cells (Figure 4F) and inside of haemocytes attached to SGs (Figure 4G). Again, circulating haemocytes did not appear to contain FRePs (data not shown).

Anti-DMF3 serum localised FRePs in surface structures above midgut cells as seen in the longitudinal section (Figure $4 \mathrm{H}$ ) and inside of several surface cells of the midgut as evident from the tangential section (Figure 4I). AntiDMF3 labelling was observed inside the salivary duct in the cytoplasm of epithelium and in the cuticular layer facing to the lumen of the salivary duct (Figures 4J,K).

\section{Identification of FRePs by mass spectrometry}

Coomassie Brilliant Blue-stained protein bands, corresponding to the positively immunostained putative FRePs, were cut off the SDS-PAGE gel, alkylated and reduced, and finally trypsin digested. Next, the tryptic peptides were analysed by mass spectrometry. The 290 $\mathrm{kDa}$ proteins from $D$. marginatus and from the three Rhipicephalus species were identified as hemelipoglycoprotein from D. marginatus (GenBank: ABD83654, Table 2). Identification of the other putative FRePs was not successful. However, examination of the hemelipoglycoprotein amino acid sequence (from D. variabilis, [4]) did not show the presence of the fibrinogen domain.

\section{Discussion}

These results provide further information about tick lectins/FRePs. In agreement with our previously published results, we detected haemagglutination activity (HA) in haemolymph of ticks Dermacentor marginatus, Rhipicephalus appendiculatus, $R$. pulchellus, and $R$. sanguineus [15]. HA was previously detected in $R$. appendiculatus and it was inhibited by GalNAc, xylose, and fructose $[21,22]$. Our results show $N$-acetylated saccharides and sialic acid together with sialylated glycoproteins as the most potent inhibitors of HA in all studied Rhipicephalus species and in D. marginatus. These observations suggest involvement of NeuAc and the $N$-acetyl groups in saccharide recognition by tick lectins/FRePs. Previously, we observed similar inhibitory pattern also for Ixodes ricinus, Ornithodoros tartakovskyi, O. pappillipes, and Argas polonicus [15].

The haemagglutinins of the tick haemolymph seem to belong to the fibrinogen-related protein family, as was shown in the case of the lectin Dorin $M$ from O. moubata which exhibited HA [8]. Haemagglutination is commonly mediated by carbohydrate specific binding and thus, by lectins [23]. Immune sera against the haemagglutination activity are therefore used for detection of unknown lectins [20].

Antigenic similarities among all examined lectins/ FRePs were confirmed by cross-reactivity of antibodies directed against these proteins among various ixodid and argasid tick species. We used the immune serum raised against the Dorin $M$ (which was purified in native state from the haemolymph of O. moubata [8]) to detect the presence of FReP proteins also in ixodid ticks. AntiDorin $\mathrm{M}$ serum reacted with four haemolymph proteins in D. marginatus (molecular weights of $38,79 / 80$, and $290 \mathrm{kDa}$ ) and with three protein in Rhipicephalus ticks (molecular weights of 58, 75, and $290 \mathrm{kDa}$ ). An additional protein with size of $45 \mathrm{kDa}$ was detected in $R$. pulchellus. Similarity of epitopes was shown for putative FRePs from $D$. marginatus, where the sera raised against the different 


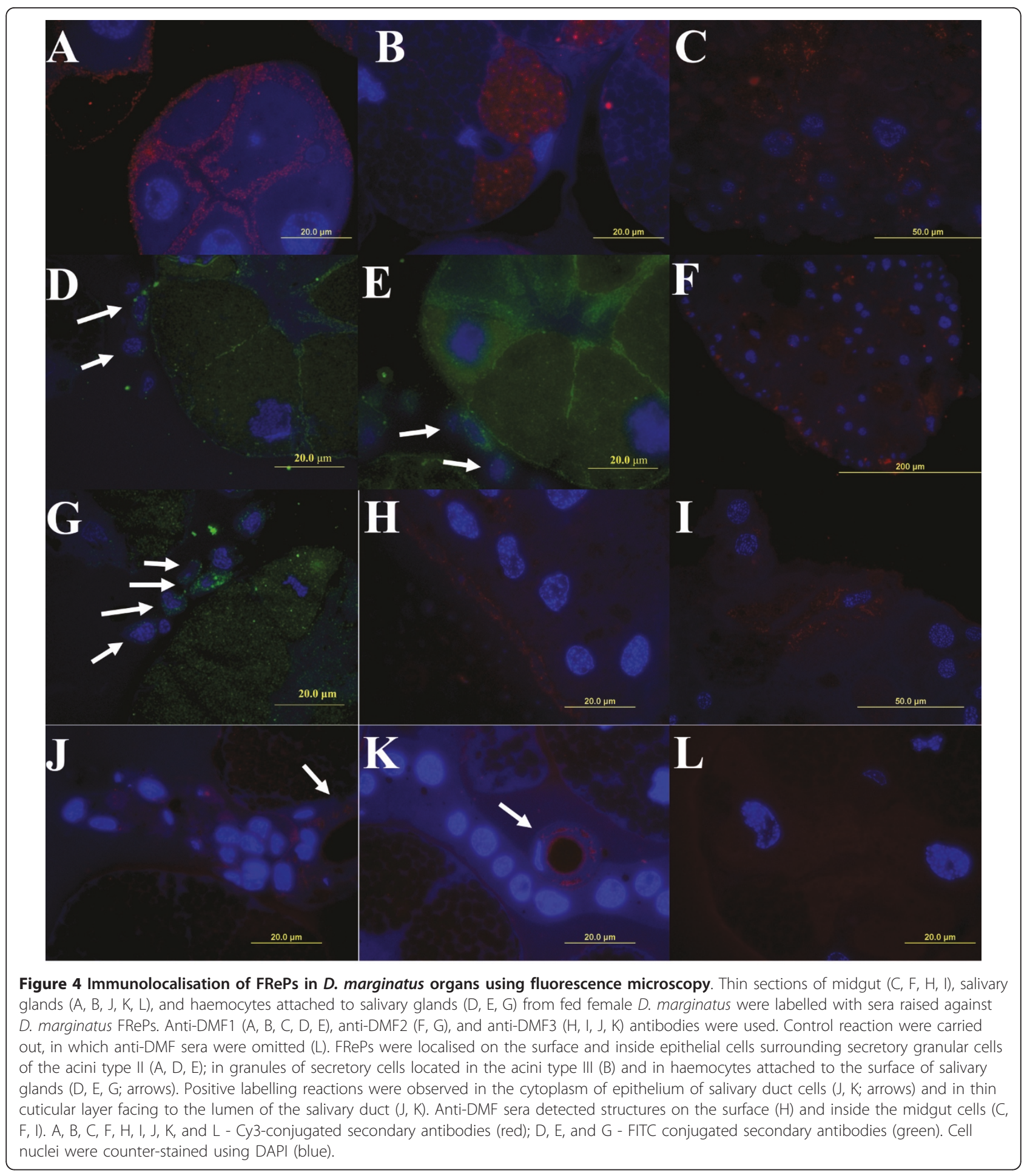

FRePs cross-reacted with all proteins. The same proteins were detected using sera raised against the HA of ticks $D$. marginatus and $R$. appendiculatus (Figures 1A, B) and I. ricinus (data not shown). These antibodies should be directed against lectin-like molecules present in the haemolymph [20]. The same staining patterns obtained using these sera and the anti-Dorin $M$ serum again suggests close relatedness of FReP proteins and the fact that they belong to lectins.

Finally, commercial antibodies directed against the fibrinogen domain of ficolin reacted with the identified putative tick FRePs (Figure 2). Except the biggest 
Table 2 Summary of the MS identification experiments performed on the $\mathbf{2 9 0} \mathrm{kDa}$ proteins from the studied ticks

\begin{tabular}{lll}
\hline & $\begin{array}{l}\text { Number of } \\
\text { repetitions }\end{array}$ & $\begin{array}{l}\text { Amino Acid sequence } \\
\text { coverage }\end{array}$ \\
\hline D. marginatus & 5 & $10.2 \%$ \\
\hline$R$. & 3 & $13.4 \%$ \\
appendiculatus & & $4.2 \%$ \\
\hline R. pulchellus & 3 & $20.8 \%$ \\
\hline$R$. sanguineus & 3 & \\
\hline
\end{tabular}

Number of MS experiments performed for identification of each of the 290 $\mathrm{kDa}$ proteins from the ticks $D$. marginatus, $R$. appendiculatus, $R$. pulchellus, and $R$. sanguineus. All the proteins were identified as hemelipoglycoprotein (D. variabilis hemelipoglycoprotein GenBank:ABD83654) and the amino acid sequence coverage is indicated for each protein.

recognised protein in each species, hemelipoglycoprotein, none of the proteins was identified by mass spectrometry. Most probably this results from the missing information on gene sequences from almost all tick species; the only known tick genome is that of I. scapularis. However, a Dorin M-like protein was identified in cDNA libraries from $D$. marginatus using degenerate primers specific for the fibrinogen domain of Dorin $M$ and other FRePs (GenBank:ACI22373) [24]. As D. marginatus hemelipoglycoprotein does not contain the fibrinogen domain, we conclude, that this protein could be one of the smaller putative FRePs identified in this study in $D$. marginatus (36 kDa or $79 / 80 \mathrm{kDa}$ proteins).

The largest of these proteins in each case were identified as hemelipoglycoprotein (HLGP). The protein was recognised by sera directed against the FReP proteins, HA of tick haemolymphs as well as against the fibrinogen domain itself. However, the protein does not contain the fibrinogen domain and therefore, the protein is not related to FRePs [3]. One of the explanation, could be epitope-similarity of the protein to the fibrinogen domain. Structural rather than sequence-similarity to other fibrinogen or other lectins is implicated also by saccharide-binding by HLGP [4]. However, reactivity of anti-fibrinogen antibodies with HLGP show, that the recognition of protein by anti-FReP antibodies does not necessarily mean the presence of the fibrinogen domain in the recognised protein.

The putative FRePs detected in this study seem to be glycosylated. Glycosylation is the common feature of lectins/glycan-binding proteins [25]. Decrease in molecular weights of the detected proteins was observed after enzymatic deglycosylation in the range of several Daltons, which corresponds to the low-mass arthropod/tick glycans $[[4,19,26]$, unpublished results]. The presented results for hemelipoglycoprotein also correspond to our previous findings [4]. In D. marginatus, a small molecular weight protein was detected after deglycosylation (34 kDa) using anti-DMF3 serum. However, the molecular weight difference is too big to be related to the glycosylation and we assume this band to represent a protease cleavage product of the $290 \mathrm{kDa}$ protein.

Further, the newly detected putative FRePs and hemelipoglycoprotein were immunolocalised in $D$. marginatus tissues. One of the FReP-specific sera labelled granules of secretory SGs acini type II suggesting secretion of the proteins to the host. The detection of FRePs in surface parts of acini type III and midgut and especially in haemocytes associated with SGs may indicate their putative innate immune functions. Surprisingly, we were not able to detect FReP proteins in freely circulating haemocytes. Tick FRePs/lectins as well as hemelipoglycoprotein are expressed in same organs as shown by detection of the proteins or their mRNA $[4,11,18]$.

Involvement of carbohydrate-binding proteins in the tick immune reaction was shown previously in the case of Theilleria parva infection of $R$. appendiculatus [27]. Thus, the detection of new members of fibrinogen-related protein family in the Dermacentor and Rhipicephalus ticks, and their further characterisation can bring new information about the tick innate immunity processes and open new ways in struggle with ticks and tick-borne diseases. Hemelipoglycoprotein, which does not contain the fibrinogen domain but seems to share structural features with FRePs was shown to bind saccharides as well [4]. In fish, vitellogenin (closely related to hemelipoglycoprotein of ticks) was shown to be directly involved in immune reaction and in recognition of carbohydrate moieties on the surface of invading bacteria [28].

\section{Conclusions}

Fibrinogen-related proteins with lectin activities are present in all studied tick species. These proteins involved in recognition of NeuAc and the $N$-acetyl groups are expressed in midgut, salivary glands as well as haemocytes attached to the salivary glands. Information about specific activities of these exemplary molecules could reveal much information on tick innate immunity processes and help in future design of anti-tick vaccines. Furthermore, cross-reactivity of antibodies against the FRePs and the fibrinogen domain itself with proteins which do not contain the fibrinogen domain point out the need for sequence analysis of proteins identified by such antibodies.

\section{Methods}

\section{Ticks}

Partially-fed females of ticks Dermacentor marginatus, Rhipicephalus appendiculatus, $R$. pulchellus, and $R$. sanguineus were obtained from the tick rearing facility of the Institute of Parasitology, Biology Centre of the Academy of Sciences of the Czech Republic in České Budějovice. Females were allowed to feed on guinea pigs for 6 days. 


\section{Haemolymph and tissue preparation}

Haemolymph was collected after cutting off a part of anterior leg of partially-fed female by fine scissors. The haemolymph from 8 to 10 females (corresponding to $10-15 \mu \mathrm{l}$ ) was collected into $50 \mu \mathrm{l}$ PBS containing protease inhibitors (Pierce). The solution was centrifuged at $4^{\circ} \mathrm{C}$ for $10 \mathrm{~min}$ utes at $100 \times \mathrm{g}$ to pellet the haemocytes. The resulting supernatant was then clarified at $23000 \times \mathrm{g}$ for 20 minutes and both the plasma (further referred to as 'haemolymph') and haemocyte fractions were stored at $-20^{\circ} \mathrm{C}$. Haemolymph was prepared for ticks $D$. marginatus $R$. appendiculatus, $R$. pulchellus, and R. sanguineus.

Midgut and salivary glands were dissected from partially-fed females of the tick D. marginatus, thoroughly washed in PBS to remove possible contamination from gut-content, and put into $0.9 \% \mathrm{NaCl}$ at $4{ }^{\circ} \mathrm{C}$ before their processing for the fluorescence microscopy analysis.

\section{Haemagglutination activity (HA) and HA inhibition}

Haemagglutination activity assays were performed as described earlier [20] using $2 \%$ suspension of rabbit erythrocytes in $0.15 \mathrm{M} \mathrm{NaCl}$ for 1 hour at room temperature. Two-fold dilution of haemolymph was prepared in U-type bottom microtitration plates. Haemagglutination buffer (50 mM Tris- $\mathrm{HCl}, 0.15 \mathrm{M} \mathrm{NaCl}, 20 \mathrm{mM} \mathrm{CaCl}$, $\mathrm{pH}$ 7.0) was used for the experiments. Reciprocal value of the last dilution of the highest sample dilution still causing visible agglutination was used as the titre of HA and the amount of haemagglutinins in this well is defined as 1 HA unit.

HA inhibition was performed in serial dilution of saccharides and glycoproteins.. Haemolymph diluted to contain 1.5 HA unit and 2\% erythrocytes suspension were added. The $50 \%$ inhibitory concentration was determined after 1 hour at room temperature as the lowest inhibitor concentration that completely inhibits the binding activity of 1.5 HA unit.

Commercial antibodies and polyclonal serum preparation Two commercial antibodies produced in rabbits were used for confirmation of epitope similarities of the studied proteins with ficolin. The first, anti-FCN1 H (HPA001295, Sigma-Aldrich), recognise amino acids 199 to 307 from the human ficolin 1 while the second, anti-FCN1 S (SAB2100804, Sigma-Aldrich), is specific for the region 180-229 of the protein. Thus, both antibodies are specific for the fibrinogen domain of the ficolin, which comprises amino acids 115 to 325 .

We have described the preparation of anti-haemagglutination activity (anti-HA) serum elsewhere [20]. Briefly, mouse erythrocytes were incubated with $D$. marginatus (serum referred to as 'anti-(DM)HA') or R. appendiculatus (serum referred to as 'anti-(RA)HA') haemolymph, washed, mixed with Freund's adjuvant in a 1:1 ratio and injected into mice. Immunisation was repeated $4 \times$ every 14 days. Blood was collected 14 days after the last immunisation. Sera were supplemented with glycerol (1:1), aliquoted and stored at $-20^{\circ} \mathrm{C}$.

Polyclonal immune sera against the $D$. marginatus FRePs were prepared using the respective proteins cut out the SDS-PAGE gel. Anti-DMF1 serum was raised against the $36 \mathrm{kDa}$ protein, anti-DMF2 against the $79 / 80 \mathrm{kDa}$ double-band, and anti-DMF3 against the $290 \mathrm{kDa}$ protein. Each protein band was cut out and homogenised with 60 $\mu \mathrm{l}$ PBS $(1 \times)$. Freund's adjuvant was added in a $1: 1$ ratio and $80 \mu$ lof this solution was subcutaneously injected to $\mathrm{BALB} / \mathrm{c}$ mice. Immunisation was repeated $4 \times$ every 14 days. Blood sera were collected 14 days after the last immunisation. Sera were supplemented with glycerol (1:1), aliquoted and stored at $-20^{\circ} \mathrm{C}$.

Mice were handled according to internal rules of the Institute of Parasitology, BC ASCR, Ceske Budejovice and the Animal Act of the Parliament of the Czech Republic.

\section{SDS-PAGE and immunoblotting}

For SDS-PAGE, haemolymph samples were diluted 1:5 in physiological buffer, mixed with loading buffer (Fermentas) and heated for $5 \mathrm{~min}$ at $95^{\circ} \mathrm{C}$. SDS-PAGE [29] was performed on $4-17.5 \%$ gradient gels. Gels were stained with PageBlue Protein Staining Solution containing Coomassie Brilliant Blue (Fermentas).

The electrophoretically separated proteins were transferred to the PVDF membrane according to [30] for 1 hour at $20 \mathrm{~V}$. The PVDF membrane was washed in PBS (14 mM NaCl, 0.15 mM KH2PO4, $1.8 \mathrm{mM}$ $\mathrm{Na} 2 \mathrm{HPO} 4,0.27 \mathrm{mM} \mathrm{KCl}, \mathrm{pH} 7.2$ ), cut into strips, and incubated for 1 hour in 5\% skim powdered milk in PBS. Strips were then incubated for 1 hour in mouse the appropriate antibodies (see above), washed with PBSTween 20 (0.05\% Tween 20 in PBS) and incubated with goat anti-mouse/anti-rabbit antibody conjugated with alkaline phosphatase (AP, VectorLabs) in 5\% milk. After incubation, strips were washed with PBS-Tween 20 and PBS. Reaction was developed in AP staining solution (VectorLabs) and after the development of sufficient signal was stopped by washing the strips several times in distilled water.

\section{Enzymatic deglycosylation}

Haemolymph samples were deglycosylated using glycosidases Endo H (New England Biolabs) or N-glycosidase F (New England Biolabs) in $50 \mathrm{mM}$ sodium phosphate buffer, $\mathrm{pH} 7.4$, overnight at $37^{\circ} \mathrm{C}$, according to the instructions of the manufacturer. Denaturation of proteins using SDS and DTT at $95^{\circ} \mathrm{C}$ for 10 minutes was performed prior the deglycosylation. Deglycosylation reactions were carried out in duplicates. 


\section{Fluorescence microscopy}

SGs and midguts were fixed in $4 \%$ formaldehyde/0.1\% glutaraldehyde in $0.1 \mathrm{M}$ phosphate buffer, $\mathrm{pH}$ 7.4 (PB) for 2 hours at $4^{\circ} \mathrm{C}$. Pieces of tissues were embedded in $10 \%$ gelatine at $37^{\circ} \mathrm{C}$, rinsed in $\mathrm{PB}$ at $4{ }^{\circ} \mathrm{C}$ and dehydrated with a gradient series of ethanol $\left(30 \%\right.$ at $0^{\circ} \mathrm{C}$, $50 \%-100 \%$ at $-15^{\circ} \mathrm{C}$ for $1 \mathrm{~h}$ ) in the EM AFS freeze substitution device (Leica). The specimens were gradually infiltrated with $25 \%, 50 \%, 75 \%$, and $100 \%$ resin LR White (Polysciences) with $0.05 \mathrm{~g}$ benzoyl methylether/ $10 \mathrm{~g}$ resin at $-15^{\circ} \mathrm{C}$. The specimens were embedded to BEEM capsules (Polysciences) and polymerised at $-15^{\circ} \mathrm{C}$ for 24 hours under UV radiation.

After polymerisation, the semithin sections were cut using the ultramicrotome EM UC6 (Leica) and dried on microscopic slides.

The sections were blocked in Tris-buffered saline, $\mathrm{pH}$ 7.4 (TBS) with $0.05 \%$ Tween-20 containing 3\% BSA for 3 hours and incubated with 1:20 anti-DMF1 or antiDMF2 or anti-DMF3 sera overnight at $4^{\circ} \mathrm{C}$. After washing in TBS, the sections were incubated with anti-mouse secondary antibody conjugated with FITC (SigmaAldrich) or Cy3 (Jackson Immunoresearch) for 3 hours at ambient temperature, washed thoroughly, and the cell nuclei were stained in $1 \mu \mathrm{l} / \mathrm{ml}$ DAPI (Sigma-Aldrich) solution for 15 minutes at ambient temperature. After washing, the sections were mounted in a solution composed of $2.5 \% \mathrm{DABCO} / 95 \%$ glycerol containing n-propyl galate $(15 \mathrm{mg} / \mathrm{ml})$ (Sigma-Aldrich) and examined using a BX51 fluorescence microscope equipped with a DP70 camera (Olympus).

\section{Mass spectrometry}

Putative FRePs were cut out the SDS-PAGE gels and reduced, alkylated, and trypsinised (ROCHE) according the manufacturer's instructions and subjected to LC-MS analysis. Peptides were separated by NanoAcquity UHPLC (Waters) on C18 silica (BEH300 column, Waters) using acetonitrile gradient $(5-80 \%)$ as a mobile phase and analysed by ESI-QTOF PREMIER mass spectrometer (Waters). The obtained data were compared to Acari non-redundant and Swiss-Prot databases using ProteinLynxGlobalServer software (Waters) under strict criteria.

\footnotetext{
Acknowledgements

This work was supported by Ministry of Education, Youth and Sports of the Czech Republic (6007665801, LC06009), Grant Agency of the Academy of Sciences of Czech Republic (KJB600960906, 206/09/1782), and the Student Grant Agency of the University of South Bohemia (SGA2008/017, SGA2009/ 017). We thank Peter Konik (Faculty of Science, University of South Bohemia) for the MS analysis, Jan Erhart (Institute of Parasitology, Biology Centre of ASCR) for the work with ticks, and Daniel Ruzek and Lenka Stifterova (Institute of Parasitology, Biology Centre of ASCR) for help with haemagglutination assays and immune sera preparation.
}

\section{Author details}

${ }^{1}$ Faculty of Sciences, University of South Bohemia, Branisovska 31, 37005 Ceske Budejovice, Czech Republic. ${ }^{2}$ Institute of Parasitology, Biology Centre of the Academy of Sciences of the Czech Republic, Branisovska 31, 37005 Ceske Budejovice, Czech Republic.

\section{Authors' contributions}

$J D, M F, J S$ conducted electrophoreses, blotting experiments, and HA assay, JD and JS participated in anti-DMF and anti-tick HA sera preparation, MV performed tick tissue preparation and together with JD performed the FM analysis, JS prepared the manuscript, and LG co-ordinated the experiments. All authors participated in the design of experiments and they approved the final manuscript.

\section{Competing interests}

The authors declare that they have no competing interests.

Received: 1 April 2011 Accepted: 5 July 2011 Published: 5 July 2011

\section{References}

1. Sonenshine DE: In Biology of ticks. Volume 2. New York: Oxford University Press; 1993.

2. Piesman J, Gage KL: Ticks and mites and the agents they transmit. In The biology of disease vectors. Edited by: Beaty BJ, Marquardt WC. Niwot, CO: University of Colorado Press; 1996:160-174.

3. Donohue KV, Khalil SMS, Mitchell RD, Sonenshine DE, Roe RM: Molecular characterization of the major hemelipoglycoprotein in ixodid ticks. Insect Mol Biol 2008, 17(3):197-208.

4. Dupejova J, Sterba J, Vancova M, Grubhoffer L: Hemelipoglycoprotein from the ornate sheep tick, Dermacentor marginatus: structural and functional characterization. Parasit Vectors 2011, 4:4.

5. Johns R, Sonenshine DE, Hynes WL: Identification of a defensin from the hemolymph of the American dog tick, Dermacentor variabilis. Insect Biochem Molec 2001, 31(9):857-865.

6. Ceraul SM, Sonenshine DE, Ratzlaff RE, Hynes WL: An arthropod defensin expressed by the hemocytes of the American dog tick, Dermacentor variabilis (Acari: Ixodidae). Insect Biochem Molec 2003, 33(11):1099-1103.

7. Chrudimska T, Chrudimsky T, Golovchenko M, Rudenko N, Grubhoffer L: New defensins from hard and soft ticks: Similarities, differences, and phylogenetic analyses. Vet Parasitol 2010, 167(2-4):298-303.

8. V K, Kopacek P, Grubhoffer L: Isolation and characterization of Dorin M, a lectin from plasma of the soft tick Ornithodoros moubata. Insect Biochem Molec 2000, 30(3):195-205.

9. Rego ROM, Kovar V, Kopacek P, Weise C, Man P, Sauman I, Grubhoffer L: The tick plasma lectin, Dorin $\mathrm{M}$, is a fibrinogen-related molecule. Insect Biochem Molec 2006, 36(4):291-299.

10. Natori S: Insect lectins and innate immunity. Adv Exp Med Biol 2001, 484:223-228.

11. Grubhoffer $L$, Kovar $V$, Rudenko N: Tick lectins: structural and functional properties. Parasitology 2004, 129:S113-S125.

12. Matsushita M, Fujita T: The role of ficolins in innate immunity. Immunobiology 2002, 205(4-5):490-497.

13. Adema CM, Hertel LA, Miller RD, Loker ES: A family of fibrinogen-related proteins that precipitates parasite-derived molecules is produced by an invertebrate after infection. Proc Natl Acad Sci USA 1997, 94(16):8691-8696.

14. Gokudan S, Muta T, Tsuda R, Koori K, Kawahara T, Seki N, Mizunoe Y, Wai SN, Iwanaga S, Kawabata S: Horseshoe crab acetyl group-recognizing lectins involved in innate immunity are structurally related to fibrinogen. Proc Natl Acad Sci USA 1999, 96(18):10086-10091.

15. Grubhoffer L, Veres J, Dusbábek F: Lectins as the molecular factors of recognition and defence reactions in ticks. In Modern Acarology. Volume 2. Edited by: Dusbábek F, Bukva V. Hague: SPBA Academic Publishing; 1991:381-388.

16. Kuhn KH, Uhlir J, Grubhoffer L: Ultrastructural localization of a sialic acidspecific hemolymph lectin in the hemocytes and other tissues of the hard tick Ixodes ricinus (Acari; Chelicerata). Parasitol Res 1996, 82(3):215-221.

17. Huang XH, Tsuji N, Miyoshi T, Nakamura-Tsuruta S, Hirabayashi J, Fujisaki K: Molecular characterization and oligosaccharide-binding properties of a galectin from the argasid tick Ornithodoros moubata. Glycobiology 2007, 17(3):313-323. 
18. Grubhoffer L, Hajdusek O, Vancova M, Sterba J, Rudenko N: Glycobiochemistry of ticks, vectors of infectious diseases: carbohydratebinding proteins and glycans. Febs J 2009, 276:141-141.

19. Man P, Kovar V, Sterba J, Strohalm M, Kavan D, Kopacek P, Grubhoffer L, Havlicek V: Deciphering Dorin M glycosylation by mass spectrometry. Eur J Mass Spectrom (Chichester, Eng) 2008, 14(6):345-354.

20. Grubhoffer L, Kováŕ $V$ : Arthropod lectins: affinity approaches in the analysis and preparation of carbohydrate binding proteins. In Techniques in insect immunology FITC-5. Edited by: Wiesner A, Dunphy GG, Marmaras VJ, Morishima I, Sugumaran M, Yamakawa M. New Jersey: SOS Publications; 1998:47-57.

21. Kamwendo SP, Ingram GA, Musisi FL, Molyneux DH: Haemagglutinin activity in tick (Rhipicephalus appendiculatus) haemolymph and extracts of gut and salivary gland. Ann Trop Med Parasitol 1993, 87(3):303-305.

22. Sebitosi ENK, Godwin GP, Young AS, Agbede RIS: Lectins in the brown ear tick, Rhipicephalus appendiculatus: detection and partial characterization. International Journal of Acarology 1998, 24(2):159-166.

23. Gabius HJ, Siebert HC, Andre S, Jimenez-Barbero J, Rudiger H: Chemical biology of the sugar code. Chembiochem 2004, 5(6):740-764.

24. Sterba J, Dupejova J, Fiser M, Golovchenko M, Rudenko N, Grubhoffer L: Identification and characterisation of lectins in several tick species. Febs J 2009, 276:88-88.

25. Sharon N, Lis H: Lectins. New York: Springer-Verlag New York, Inc; 2007.

26. Pedra JH, Narasimhan S, Rendic D, DePonte K, Bell-Sakyi L, Wilson IB, Fikrig E: Fucosylation enhances colonization of ticks by Anaplasma phagocytophilum. Cell Microbiol 2010, 12(9):1222-1234.

27. Kamwendo SP, Ingram GA, Musisi FL, Trees AJ, Molyneux DH: Characteristics of tick, Rhipicephalus appendiculatus, glands distinguished by surface lectin binding. Ann Trop Med Parasitol 1993, 87(5):525-535,

28. Zhang SC, Li ZJ, Zhang J, Liu M, Liu ZH: Vitellogenin is a cidal factor capable of killing bacteria via interaction with lipopolysaccharide and lipoteichoic acid. Mol Immunol 2009, 46(16):3232-3239.

29. Laemmli UK: Cleavage of structural proteins during assembly of head of bacteriophage-T4. Nature 1970, 227(5259):680-\&.

30. Towbin H, Staehelin T, Gordon J: Electrophoretictransfer of proteins from polyacrylamide gels to nitrocellulose sheets - procedure and some applications. Proc Natl Acad Sci USA 1979, 76(9):4350-4354.

doi:10.1186/1756-3305-4-127

Cite this article as: Sterba et al:: Fibrinogen-related proteins in ixodid ticks. Parasites \& Vectors 2011 4:127.

\section{Submit your next manuscript to BioMed Central and take full advantage of:}

- Convenient online submission

- Thorough peer review

- No space constraints or color figure charges

- Immediate publication on acceptance

- Inclusion in PubMed, CAS, Scopus and Google Scholar

- Research which is freely available for redistribution

Submit your manuscript at www.biomedcentral.com/submit 